\title{
Josefa Verride y Martina de los Ángeles. E1 difícil camino hacia la santidad.
}

\author{
Josefa Verride and Martina de los Ángeles. The difficult way to \\ holiness.
}

\author{
Ana Morte Acín \\ anamorte@unizar.es
}

Universidad de Zaragoza

\begin{abstract}
Resumen: A través de la información que nos proporcionan las vidas de Josefa Verride, tercera de la orden dominica en Huesca y Martina de los Ángeles, religiosa de la misma orden, fundadora del convento de san Pedro de Benabarre, pretendo aportar nuevas ideas acerca del proceso de adquisición de la fama de santidad de algunas mujeres en la Edad Moderna española. Las órdenes religiosas debieron idear estrategias que ayudasen a legitimar y consolidar la fama de santidad de estas mujeres. Una de estas estrategias fue la vinculación de las religiosas con otras mujeres con fama de santidad, creando genealogías femeninas que les permitiesen perpetuar su memoria y prestigio a lo largo del tiempo.
\end{abstract}

Palabras clave: santidad femenina, memoria, genealogías femeninas, Martina de los Ángeles, Josefa Verride

\begin{abstract}
Through the information provided to us the lives of Josefa Verride lay sister of dominican order in Huesca and Martina of the Angels, nun of the same order, founder of the convent of s. Pedro in Benabarre, I intend to bring new ideas about the process of acquiring reputation of holiness of some women in the Early Modern age in Spain. Religious orders had to devise strategies that helped legitimize and consolidate the reputation of holiness of these women. One of these strategies was to link them with other women religious with a reputation for holiness, creating female genealogies to enable them perpetuate their memory and prestige over time.
\end{abstract}

Keywords: Female sanctity, imagen, memory, female genealogies, Martina de los Ángeles, Josefa Verride 
En los últimos años se ha asistido a un significativo aumento de los estudios sobre religiosidad femenina que han servido para rellenar algunas de las grandes lagunas existentes, pero también para abrir nuevas vías de investigación y plantear interpretaciones novedosas de algunos de los temas más conocidos. Una de estas propuestas tiene que ver con la construcción tanto de la imagen como de la memoria de estas mujeres. La memoria es una de las materias a las que la historiografía actual está prestando mayor atención y por tanto parece oportuno que desde el mundo de la religiosidad femenina también se atienda este campo de estudio.

Al analizar las vidas y hagiografías de mujeres con fama de santidad una de las cuestiones que aparece nítida ante nosotros es la relación que había entre las habitantes de los conventos y el exterior. Lejos queda ya la idea de que los muros de los claustros eran infranqueables y que la clausura se cumplía a rajatabla. Como bien han demostrado estudios recientes (Atienza 2014) la relación entre interior y exterior era rica y fluida. Por tanto, si esa relación existía cabe preguntarse qué imagen tenían de estas mujeres los fieles y las gentes de las poblaciones en las que vivían, cómo se construía esa imagen y qué memoria se guardaba de ellas tras su muerte. A lo largo de las siguientes páginas sirviéndome del caso de Josefa Verride y Martina de los Ángeles plantearé algunas de las estrategias e instrumentos que las órdenes religiosas usaron, precisamente, para elaborar y perpetuar la imagen de santidad de las religiosas.

Las principales fuentes con las que contamos para conocer la existencia de las mujeres con fama de santidad son las obras de carácter biográfico y los procesos de beatificación. Ambas tienen el elemento en común de que las órdenes religiosas jugaban un papel fundamental tanto en la elaboración como en la difusión de las mismas. Como bien señalaba Poutrin (1995:203) había una selección entre la multitud de candidatas en función de las posibilidades de alcanzar los altares que tenía cada una de ellas. Todo lo anterior nos lleva inevitablemente a la cuestión de cómo alcanzaban la fama de santidad estas mujeres.

A este respecto, en los últimos tiempos se ha ido poniendo de relieve la importancia que tuvo la relación de estas mujeres con sus vecinos a la hora de darse a conocer y atraer la atención de la población. En el caso de que se llevara a cabo un proceso de beatificación era muy importante que la gente participase y expusiera la relación que habían tenido con la religiosa, por lo que la memoria que se guardaba de ellas era también crucial, máxime cuando los procesos se alargaban durante años y muchas veces las testificaciones se producían tiempo después de que la religiosa hubiera fallecido.

Muy pocas consiguieron alcanzar el grado de beatas o venerables, pero también muy pocas consiguieron trascender más allá de su tiempo y ser recordadas por las siguientes generaciones. Más allá de las grandes figuras como sor María de Ágreda, María Vela o Luisa de Carrión hay un gran número de mujeres que se supone gozaron de fama de santidad durante su vida, pero cuya memoria 
se pierde poco tiempo después de su muerte. Hay al respecto ejemplos de Vidas que se redactan años después del fallecimiento de las protagonistas con el objetivo precisamente de mantener una memoria que se estaba perdiendo incluso por parte de las religiosas de la congregación. Tal es el caso, por ejemplo, de la vida de Mariana Villalba y sus hijas, escrita por el P. Faci, (1761:79) según sus palabras, porque ni siquiera en la congregación se guardaba memoria de sus vidas.

Así pues, ¿Qué elementos eran importantes para mantener esa memoria viva? Por una parte está el papel de la gente y su implicación en esa preservación de la memoria. Una de las características que suele repetirse, salvo excepciones, en los casos de más éxito es el arraigo en poblaciones de pequeño o mediano tamaño. Es lógico que pudieran ser más conocidas por la población si eran miembros de la comunidad y además esa comunidad era pequeña. Las fundadoras, que se trasladaban a otras localidades y empezaban allí de cero, sobre todo si se trataba de ciudades, parece que estrechaban menos lazos con la población y la construcción de su santidad se basaba más en las facetas puramente espirituales. También habría que señalar que en las ciudades o núcleos de población más grandes habría mayor número de conventos y congregaciones por lo que, si se permite la expresión, aumentaría la «competencia» en comparación con las poblaciones de menor tamaño.

El segundo factor, quizá el más decisivo, era la actitud y la actividad de la orden religiosa. Que la orden iniciara un proceso, que mandara redactar una vida o se publicara una autobiografía que potenciase de alguna manera la imagen de la religiosa era imprescindible para mantener viva su memoria. Sin embargo, aunque los procesos de beatificación se pusieran en marcha tras la muerte de la supuesta santa, la actividad en pos de aumentar y afianzar esa fama de santidad solía empezar mucho antes. De hecho, es habitual observar cómo las órdenes religiosas siempre ávidas de contar entres sus filas con el mayor número de personas con fama de santidad posible, posibilitaban la actividad y la publicidad de las actuaciones de las religiosas a fin de que fueran conocidas y aumentara el número de seguidores. (Atienza 2012)

En este sentido una de las estrategias de éxito, desde mi punto de vista, fue la capacidad de generar algún tipo de genealogía de santidad femenina que las incluyese y las pusiera en relación tanto con mujeres que en el pasado habían gozado de fama de santidad y eran conocidas y reconocidas por ello, como con las futuras generaciones. De este modo, la fama de santidad de la religiosa pasaba a formar parte de una tradición, siendo así más sencillo mantener su memoria, tanto para la orden como para la población. Este es el caso de las dos mujeres de las que me voy a ocupar. En principio ninguna fue en su momento una gran figura, y la repercusión que tuvieron en sus lugares de residencia parece que fue limitada pero la orden dominica encontró la manera de vincularlas a sendas tradiciones que permitieron que se guardara memoria de ella en las siguientes generaciones. 


\section{Martina de los Ángeles y Josefa Verride}

Estas dos religiosas aragonesas pertenecieron a la orden dominica. Martina nació en Villamayor, población cercana a Zaragoza en 1573 y murió en Benabarre 1635. Fue profesa en el convento de Santa Fe de Zaragoza y, posteriormente en 1632 fue enviada como fundadora del convento de San Pedro Mártir a Benabarre, en la provincia de Huesca. Por su parte Josefa Verride nació en Huesca en 1658 y murió en la misma ciudad en 1716. En su caso fue tercera de la orden.

Ambas mujeres cuentan con biografías llevadas a cabo por miembros de su orden y también en los dos casos se inició un proceso de beatificación que no prosperó. Según el autor de la vida de Martina de los Ángeles, tras la recogida de testimonios el proceso de beatificación se envió a Roma pero el encargado de llevarlo murió por el camino y el proceso de perdió con él. La otra copia afirma que permanecía en el convento de Benabarre y que la tenía él en su poder. (Maya 1678: prólogo s.p.) Lo cierto es que, efectivamente, hace referencia a testimonios del proceso en la Vida, algo por otra parte muy habitual.

Tanto Martina como Josefa tuvieron una infancia difícil. Isabel de Estadilla, madre de Martina murió en el parto y el padre, Bernabé de Arilla contrajo segundas nupcias con otra mujer. La madrastra no debía llevarse muy bien con la niña y el padre tomó la determinación de enviarla con una pariente (María Sanz) desde los 6 años hasta que tomó el hábito, no se sabe exactamente a qué edad. A partir de este momento el relato de su vida obedece al patrón hagiográfico típico caracterizado por una piedad precoz y un rechazo a los pasatiempos y actividades propios de su edad. (Maya 1678: 1-25)

En el caso de Josefa, su vida, ya desde su infancia, estuvo marcada por la enfermedad. A pesar de ser la hija mayor, será su hermana pequeña la que se case y ella toma el camino religioso, puede ser porque desde los 8 o 9 años estaba ciega y eso pudo influir en que la familia apostara por la hermana pequeña para que se casase, ya que ni en la vida ni en el proceso de beatificación se hace referencia a que hubiera nunca ningún plan de casar a Josefa y tampoco de que entrase en un convento.

También en este caso la niñez de Josefa está caracterizada por la piedad y el recogimiento, además de, como he señalado, por la enfermedad, que le provocó la ceguera y estuvo a punto de costarle la vida.

A los 18 años tomó el hábito de la tercera orden de S. Domingo (1676). Siendo la primera que lo hacía en Huesca de esa orden y sin que hubiese un beaterio o se vinculase a un convento. Ella vivía en casa de sus padres donde ayudaba con las tareas domésticas y realizaba sus actividades devocionales. (López Franco 1730: 1-12) La entrada en religión de Josefa no estuvo exenta de dificultades. La primera era, efectivamente, la inexistencia de un beaterio que estuviera vinculado al convento dominico. En la década de los 70 del siglo XVII la existencia de beatas que vivieran fuera de beaterios y la existencia de estos mismos se había visto sensiblemente reducida, aunque, como en el caso de Josefa se pueden seguir encontrando casos. Que viviese en casa de sus padres y por 
tanto, estuviera recogida y tutelada por los miembros de su familia fue un elemento legitimador para que Josefa pudiera tomar los hábitos de la tercera orden, ya que la supervivencia de los beaterios fue unida en gran medida a que no supusiesen escándalo y estuvieran bien integrados en la comunidad. La función social de los beaterios en el marco de lo local, que aún debe estudiarse con mayor profundidad, está siendo puesto de relieve cada vez por más estudiosos, y se está empezando a desterrar la idea de que los beaterios tras Trento fueron sistemáticamente perseguidos y estigmatizados. Como señala Ángela Atienza (2007: 167), muchos beaterios después del Concilio continuaron contando con el apoyo y el respaldo tanto eclesiástico como social, fundamentalmente aquellos que no ocasionaban problemas, en los que se vivía de acuerdo a los ideales de honorabilidad deseables para las mujeres y que se encontraban perfectamente integrados en la vida cotidiana de la localidad.

La vida de Martina tiene la particularidad de que tras unos años en el convento de Santa Fe en Zaragoza fue enviada como fundadora a Benabarre. Allí tuvo que enfrentarse a las dificultades propias de las fundaciones, fundamentalmente la escasez de medios para subsistir y allí también forjó su fama de santidad.

La extracción social de ambas mujeres es bastante diferente, mientras que el padre de Martina era hidalgo, los padres de Josefa según su relato tenían «el honesto oficio de cubería y algún poco de labor» (López Franco 1730:2), puede que la falta de recursos económicos junto a la ceguera de Josefa fueran las causas de que a pesar de sus deseos no entrara como religiosa profesa a un convento sino como tercera, lo que le permitía seguir viviendo en casa de sus padres.

El relato de la muerte de ambas está también impregnado de tintes hagiográficos. La muerte ejemplar y la actitud resignada y paciente ante la enfermedad son dos de las características del santo barroco y las podemos encontrar en prácticamente todas las vidas de la época (Sánchez Lora 1988).

En los dos casos encontramos también ejemplos de cuál era la relación de la religiosas con la población. Como he señalado al inicio, uno de los pilares en los que se sustentaba la fama de santidad de una mujer era la aprobación de la sociedad, por lo que estas mujeres debían mantener un discurso y una «performatividad» creíble para los fieles, que les permitiese mantenerse a flote en una sociedad a veces muy hostil para ellas y en las que se hallaban permanentemente bajo sospecha. ${ }^{1}$ La manera de interactuar con los que las rodeaban, el grado de identificación entre el modelo teórico y la puesta en escena que la mujer llevara a cabo estaban en la base de su éxito o su fracaso, puesto que los fieles jugaban un papel fundamental en la validación o no de su santidad.

Las mujeres con fama de santidad actuaban como consejeras no solo en temas puramente espirituales sino también en cuestiones que afectaban a la vida cotidiana de los fieles. Dos son los ámbitos en los que se concentran el grueso de las actuaciones: el familiar y el de la salud. Abundan los casos de mujeres que intervienen ante casos de maltrato, asunto del que ya me ocupé en otro

1 Sobre el concepto de performatividad en la actividad de las místicas, ver Sanmartín Bastida (2012) 
lugar, pero también son habituales los consejos sobre la conveniencia o no de contraer matrimonio con determinada persona, o sobre la pertinencia de entrar en religión y en qué orden hacerlo. (Morte Acín 2014)

Sin embargo, son los temas relacionados con la salud los que se repiten con mayor frecuencia en la documentación, destacando las curaciones relacionadas con mujeres embarazadas y con niños. Esta labor como consejeras y sanadoras fue una de las claves para entender el prestigio y el reconocimiento del que gozaron entre la población, ya que en estos casos, «el santo actuaba en la comunidad haciendo la competencia a otros poderes como la medicina y la magia, que sucumbirán al poder taumatúrgico del santo». (Zarri 1980: 371)

En el caso de las mujeres que nos ocupan también encontramos testimonios de este tipo. De Martina de los Ángeles existen ejemplos correspondientes fundamentalmente a su época en Benabarre, aunque también los haya de cuando vivía en el convento de Santa Fe de Zaragoza. De todos los prodigios que se narran sobre Martina los que nos interesan aquí son los relacionados con las curaciones, y muy especialmente las que se producían por medio de cuentas de rosario, cruces y otros objetos bendecidos ya que son las que la conectan con una tradición, ya existente desde los tiempos de Juana de la Cruz, que fue la herramienta utilizada por la orden como elemento vertebrador de su fama de santidad. Con Martina de los Ángeles la orden dominica lo que hizo fue incluirla en una genealogía de mujeres con fama de santidad que obtenía de la divinidad cuentas, cruces y objetos con dones sobrenaturales.

\section{Martina de los Ángeles y las cuentas de la Madre Juana}

Una de las primeras referencias que conocemos del uso y obtención de este tipo de objetos proviene de la beata Juana de la Cruz. Esta beata comenzó a repartir entre sus seguidores cuentas de rosario, que durante uno de sus raptos místicos había llevado al Cielo donde habían sido bendecidos por Dios. Posteriormente se dieron más casos de religiosas que también repartían cuentas u otros objetos bendecidos por Dios durante algunos de sus éxtasis, como Luisa de la Ascensión, María de Ágreda, Águeda de la Cruz o la propia Martina de los Ángeles, convirtiéndose en una práctica relativamente habitual (Poutrin 1990: 33-39).

Juana de la Cruz obtenía de la divinidad cuentas de rosario, cruces y otros objetos que contaban no solo con la bendición divina sino con diversas propiedades. Martina conocedora de esas propiedades quiso ella también conseguir el mismo favor. Así es el relato que hace su biógrafo de la obtención de estos objetos:

Como llegó esta venerable madre a ser tan favorecida de su divino esposo, que la subían dos vezes al día los ángeles al cielo, con el ardentísimo deseo que tenía de que todos participasen de su infinita misericordia, subía muchas vezes cargada de cruzes y rosarios, y le pedía les echase su bendicion y comunicara alguna virtud de sus merecimientos infinitos, para que los 
que las llevaran, hallaran algún alivio a sus trabajos, assí espirituales como corporales. [...]» (Maya Salaberría 1678: 122)

La propia Martina se incluía en esa tradición iniciada por Juana de la Cruz afirmando: «Como a mi Dios y Señor le pido algunas vezes me haga merced de bendecir algunas cuentas, cruces y rosarios en el cielo para bien de las almas y cuerpos, me las bendice». (Maya Salaberría 1678: 123)

Algunos de los casos en los que se produjeron curaciones gracias a las cuentas y cruces los encontramos perfectamente narrados en su vida:

Había en Villamayor, patria de la Venerable Madre sor Martina, un niño totalmente baldado y estando en una ocasión en la calle, compadecido Jaime de Alfranca de verle tan impedido sacó una cruz que tenía de la Venerable Madre sor Martina y en presencia de muchos se la aplicó al niño y al instante se levantó del suelo bueno y sano, y empezó a correr por el lugar con admiración de todos (Maya Salaberría 1678: 125).

Otro caso también relacionado con un niño pequeño enfermo es el siguiente:

María Castillo natural de Villamayor, tenía un hijo muy pequeño al cual maltrataba mucho una quebradura que padecía. Aplícole a ella una Cuenta que le había enviado la misma Venerable Madre sor Martina y después de tres o cuatro días, al quitarle las vendas lo halló bueno y sano y nunca más padeció ese achaque. Ella misma lo depone (Maya Salaberría 1678: 125).

Además de los casos expuestos, se buscó legitimar a Martina a través de la aprobación de los miembros masculinos de su orden, elemento imprescindible para cualquier religiosa. A este respecto Maya Salaberría hace referencia de la siguiente manera a la opinión favorable que algunos de ellos tenían de la religiosa:

Concuerda con la Venerable Madre sor Martina lo que el muy Reverendo Padre Fr. Gabriel Ximenez, su confesor, varón de tan acreditada virtud (...) escribió en varias cartas al Padre Fray Juan Miguel Navarro(...) remitiéndole a Zaragoza de esas Cruzes y Cuentas. En una de ellas dize así: Concluyo con dezir: que la religión tiene en estos tiempos un prodigio que ha de ser de admiración al mundo, consuelo de muchas almas y crédito de la religión. La cuenta va así: las virtudes que Dios ha puesto en ellas son muchas: y quando no tuvieran otras que averlas tenido la Virgen Santísima en sus manos, darles la bendición del hijo y comunicarles las virtudes que a las de la santa Juana y aún mayores bastaba para que el mundo haga estimación de ellas (Maya Salaberría 1678: 123).

El hecho de vincular a Martina con la tradición de la madre Juana e incluirla en esa cadena de mujeres que obtenían objetos benditos ayudó a que la memoria de la religiosa traspasara los límites de su comunidad en Benabarre y que también se mantuviera en el tiempo. Para demostrarlo expondré dos ejemplos. El primero corresponde a la otra protagonista del trabajo, Josefa Verride, puesto que en su biografía aparecen menciones a Martina de los Ángeles. La relación que se creó entre las dos mujeres no debe pasar inadvertida. 
El camino hacia la santidad de la tercera dominica no fue nada sencillo. Ya he aludido a su baja extracción social y a que el hecho de ser beata a finales del siglo XVII no le auspiciaba un futuro muy halagüeño. Josefa tuvo problemas para ganarse la confianza de sus confesores que casi siempre la miraron con recelo, y tuvo incluso que enfrentarse a la Inquisición. Efectivamente, en 1693, ante las dudas expresadas por uno de sus directores espirituales, fue llevada a Zaragoza para que la examinara el Santo oficio que determinó finalmente que se trataba de un espíritu bueno. Pero unos años más tarde, cuando su confesor tuvo que irse de Huesca, los nuevos directores que tuvo empezaron de nuevo a dudar de ella y se quedó sola, sin nadie que la guiase y la confesase.

La falta de confesores que confiasen en ella fue una constante en su vida y en algunos periodos se quedó sin guía espiritual ante la renuencia de los dominicos a procurarle uno. Junto con el P. Arcos el confesor que más influyó en ella fue su biógrafo, Pedro López Franco que hacia 1709 se encargó de su dirección espiritual. López, a pesar de admitir que no estaba igual de bien preparado que un fraile, ante lo necesitada que la veía consiguió el permiso de los dominicos.

Es a partir de este momento cuando aparecen en su vida alusiones directas a Martina de los Ángeles. Las referencias a mujeres bíblicas y de la tradición cristiana como Gertrudis de Helfta, Catalina de Siena era muy habitual, así como la mención a otras mujeres con fama de santidad contrastada, o al menos no puesta en duda. Por eso es relevante y me parece una prueba de que la santidad de Martina se consideraba legítima que se la cite en la biografía de Josefa.

En la Vida de Josefa se relata cómo el espíritu de Martina le era enviado para animarla y no dejar que decayese su ánimo. La religiosa aparece como una figura de reconocido prestigio, cuya santidad no es cuestionada. Hay varios ejemplos pero citaré solo dos:

\footnotetext{
El espíritu que también se le apareció muchas vezes y la animó en instruyó fue el de la Venerable Sierva de el Señor Sor Martina de los Ángeles y Arilla, también dominicana. Esta alma fue embiada de el Cielo a la Venerable Josepha para que esta correspondiese a su Magestad cooperando a la transfusión de los dotes del cuerpo, que quería hazer en ella, para emplearla en exercicios de caridad a lo Angelico en cuerpo y alma a imitación del camino de la misma Arilla (López Franco 1730: 345).
}

Para animarla e instruirla la enviaba el señor a su desierto o retiro visitas soberanas. Día trece de abril se le apareció el espíritu de la Venerable Sierva de Dios Martina de los Ángeles o Arilla, el qual animó a Josefa a que diese el consentimiento y no embarazase el recibo de los dones para la imitación de Cristo (López Franco 1730: 65).

Existe una referencia además a que Josefa también obtenía cuentas y cruces bendecidos y aunque no se cita a Martina explícitamente parece razonable que estuviera incluida en el grupo de religiosas del que se habla, ya que tanto el autor como Josefa conocían la vida y fama de Martina.

Por el mismo tiempo primero, en que la favorecía con tan frequentes visitas, le concedió su Magestad la merced de echarla bendiciones, y concederla gracias, por sí, o por sus Santos, en los Rosarios, Cruxes, Cíngulos y otras alhajuelas de devoción de modo que se estimaban y 
estiman mucho por esta bendición y gracias que el Señor les concedía como lo ha hecho por medio de otras siervas suyas para los que con pía, pura fe y debida disposición las tengan o traigan consigo (López Franco 1730: 19).

Pero la presencia de Martina en la Vida de Josefa no sólo servía, en mi opinión, para reforzar la fama de santidad de Martina sino que también ayudaba a legitimar la figura de Josefa, puesto que si una mujer como Martina, de cuya santidad parece que no había duda, alienta y anima a Josefa a que transite el camino que le marca su confesor, era porque Josefa era merecedora de alcanzar la santidad. Se produce así una retroalimentación entre las dos mujeres contribuyendo a sustentar la una la fama de la otra.

El segundo ejemplo lo encontramos ya bien entrado el siglo XVIII, concretamente en 1761. Ese año el P. Roque Faci publicó Vida de la V. Mariana Villalva y Vicente, y la de sus tres hijas Sor María, Sor Margarita y Sor Mariana Escobar. En esta obra el autor recogía la vida de Mariana Villalba, beata de san Vicente de Paul y sus tres hijas, carmelitas en el convento de la Encarnación de Zaragoza, que vivieron en la primera mitad del silgo XVII. En los capítulo dedicados a la vida de la hermana pequeña, sor Margarita Escobar, se hace alusión a la presencia de reliquias de sor Martina de los Ángeles en la Encarnación de Zaragoza.

Durante la enfermedad de una de sus hermanas, sor Margarita cogió una carta de sor Martina de los Ángeles que había en el convento, se la aplicó en el estómago y al instante la enferma mejoró. En el relato Faci añade, además, que en el convento había otras reliquias de esta religiosa, como una basquiña interior, una toca y varias cuentas. (Faci 1761: 460) Hay dos elementos a tener en cuenta sobre esta cuestión. El primero es que las reliquias pertenecientes a Martina de los Ángeles están en el convento y son usadas como tales en 1631, según la biografía del padre Faci, es decir, cuatro años antes de la muerte de Martina, que se produjo en 1635, más de cuarenta antes de que se publicase su biografía (Maya Salaberría 1678). Es decir, se refuerza la hipótesis de que la fama de santidad de Martina se había extendido desde Benabarre en vida de esta, y que no se circunscribía al ámbito dominico. Y en segundo lugar, que bien entrado el siglo XVIII, al P. Faci le sigue pareciendo oportuno incluir a esta mujer entre las mencionadas en la biografía, señal inequívoca de que su nombre seguía en la memoria colectiva y era fácilmente identificable.

Pero como he señalado, lo que se buscaba con este tipo de estrategias era no sólo legitimar la fama de santidad de la mujer sino conseguir perpetuar su memoria. Así que cabría preguntarse si fue así en el caso de Martina. La repuesta sería afirmativa, al menos en Aragón y hasta bien entrado el siglo XVIII. La pregunta que se plantea a continuación y que resultaría de interés investigar, sería cuál fue el alcance de esta estrategia, es decir, si se trataba de una figura conocida solamente en Aragón, si se considera por tanto un «culto» local o si se puede rastrear su presencia en otras religiosas sin vinculación con el reino. 


\section{Josefa Verride y la fundación de un beaterio}

En el caso de Josefa Verride la manera de preservar su memoria fue diferente. Sin duda se trataba de un caso difícil tanto por sus características, ya que se trataba de una beata, como por la cronología, principios del siglo XVIII, cuando el fenómeno de las beatas se encontraba en retroceso ante el avance de los preceptos tridentinos.

Si se lee la vida de Josefa tampoco se pueden encontrar episodios especialmente destacables más allá de las típicas curaciones. No se sabe que mantuviera ningún tipo de contacto con personas influyentes y desde luego no parece que fuese una figura de una gran relevancia en la ciudad. De hecho, es el propio autor, el que afirma que se tenía poco conocimiento de la vida de Josefa, aunque lo achaca a que vivía retirada en su casa y por tanto tenía poco contacto con el exterior:

La singular fama de virtud y santidad con que vivió y murió [...] estimuló los deseos de diferentes personas devotas y pías, de tener alguna noticia de su vida portentosa, con tanta mayor ansia, cuanto se sabía menos de su carrera por haber sido tan retirada y oculta y por eso tal vez más misteriosa, como acontece en la fábrica de las abejas que se hace en oculto retiro y por eso comparó a ella la de la gracia san Macario. (López Franco 1730 dedicatoria s.p.)

Sin embargo, también para ella se encontró un modo de preservar su memoria, en su caso además, una memoria que perdura hasta nuestros días.

En el apartado dedicado al don de profecía de la biografía de Josefa Verride, se cuenta cómo esta tuvo una tuvo una visión en la que se le dio a conocer que se iba a fundar un beaterio en su casa y que esa obra sería su legado.

Muy célebre fue en esta iluminada Virgen la profecía que le hizo repetir su Magestad de el Colegio o casa de Beatas que se avia de erigir en Huesca como fruto de su espíritu maternal, y con el título de Santa María Magdalena. (López Franco 1730: 328)

A esta profecía en la Vida se le dedican varias páginas en las que se pormenorizan los detalles y se hace hincapié en que acogería a mujeres piadosas a las que llama rosas e incluso se menciona que la priora sería María Lay. El beaterio se compondría de 12 mujeres y estaría bajo la advocación de santa María Magdalena.

No será importuno referir aquí algunas de las promesas y revelaciones que el Señor hizo a su Esposa acerca de esta casa. Día 24 de setiembre de 1711 le mostró su Magestad con luz superior que la comunicaba espíritu maternal, dándole a entender que por ella llamaría azía sí otras Vírgenes, singularmente para estar en junta o colección de Beatas y que entre las hijas de su espíritu, sería principal sor María Lay, y otra de fuera de Huesca por la qual derramaría la bendita sierva sangre como se verificó después por caridad, para que tal persona siguiese el camino por donde el Señor la llamaba. (López Franco 1730: 328)

Y así se ha cumplido en gran parte hasta ahora: porque apenas murió la Venerable Josepha a la vista aún de su cadáver caliente, se sintieron algunas doncellas, llamadas para imitarla y seguirla en el Instituto de la Tercera Orden de Penitencia, como queda insinuado arriba. Otras después visitando su sepulcro y otras al oír la fama de su santidad. De modo que el día 22 de julio del 
año 1725 entraron tres en la casa, que un devoto les compró de limosna, tomando el título de Santa María Madalena que era el que su Magestad insinuó a su Esposa, avía de tener aquella fundación y casa (López Franco 1730: 386-387).

Como era habitual en las fundaciones la figura de los benefactores era fundamental. En este caso aunque no se dicen los nombres sí se menciona a dos personas que contribuyeron materialmente a la consecución del proyecto. La primera donó, aún en vida de Josefa, veinticinco cahízes de trigo, que no resultaron suficientes para emprender la obra. La segunda, más determinante, se encargó de comprar la casa en la que se fundaría el beaterio, 8 años después de la muerte de la religiosa.

Las dificultades para llevar a cabo la fundación son un elemento crucial en la construcción de la imagen y la memoria de Josefa. Parece ser que la idea era vincularla con el beaterio de manera que así su nombre pudiera perdurar en el tiempo. A ello apunta también la propia narración de la visión de Josefa en la que la propia divinidad le habría expresado esta idea:

Otra ocasión hablando su Esposo Christo a la Venerable con gran familiaridad, la dio a entender, que la palabra de sus Rosas (assí llamaba a las Beatas) se efectuaría con el tiempo y sería obra de su pensamiento y no mundana, por lo qual subsistiría. Después día 30 de deziembre de 1714 se le apareció Christo delante con presencia intelectual y aviendo experimentado de la visita efectos muy soberanos entendió de su Magestad Divina que cumpliría a su tiempo la sobredicha promesa.

Muchas vezes manifestó el Señor a su sierva el espíritu maternal en el árbol de la mostaza. Singularmente, día 25 de marzo de el año de 1715 la dio a entender que por ella daría luz para curar muchas almas palomas y al mismo tiempo se veía la Venerable interiormente como un árbol de mostaza, y en él muchas aves o palomas y al Señor en el mismo árbol. En lo qual entendía que muchas almas se labrarían con la luz y caridad maternal de su espíritu, singularmente las de la Casa de Rosas o Beatas (López Franco 1730: 329).

Así pues, ante la patente imposibilidad de que la obra se concluyera en vida de Josefa y que ella fuera la que acogiese y guiase a las primeras beatas, el relato se adapta y aboga por la autoría intelectual de Josefa. Muy elocuente también es la comparación con el árbol de la mostaza, una imagen plástica y evocadora. La constatación de que el plan original era que la fundación se produjera en vida, nos la da propia narración de las visiones de la religiosa. En una de ellas se percibe perfectamente como hubo intentos de conseguir que se produjera antes pero que no pudo ser y se atribuye este cambio a los planes divinos

Sucedió esta predicción quando la governaba el Presentado Arcos aún, en cuyo tiempo para la obra alargó una persona pía 25 cahizes de trigo pero por mas que se Magestad Divina iba alumbrando aquella idea nunca se ofrecçia coyuntura ni parece la avía de aver según la mala disposición. Pero cumpliose en fin después de la muerte de la Venerable aviéndose reservado para sí el Señor la llave del tiempo y la razón en que se avía de efectuar dicha planta, la qual se comenzó después del año de 1725 día de Santa María Magdalena a 22 de julio (...) ocho años después de muerta la Venerable (López Franco 1730: 328). 
La preocupación de la religiosa por la demora en la puesta en marcha del proyecto era una constante

Seis meses antes de su muerte le bolvió su Magestad a confirmar lo mismo, a saber es que se llegaría a plantar dicha casa, y que ella avía de ser el fundamento, y morir la primera. Mandole a más el Señor, que lo pidiese por medio de su Madre Santísima. Sin embargo, la Venerable andaba siempre temerosa e incrédula, a veces, no alcanzando el quando, ni el modo con que ella avía de ser el fundamento, y la Madre de aquella fundación insigne (López Franco 1730: 329).

También sus discípulas dudaban de la viabilidad de la fundación y era Josefa las que les instaba a confiar en la Providencia

Otras veces se lo daba el Señor a entender mostrándole unas Palomas muy blancas y se entendía eran doze en el número. Otras, proponiéndole en espíritu, un Joyel hermoso con muchas piedras preciosas y brillantes, y en medio una mayor y de mayor brillantez que era ella. A sor María Lay su compañera individua que sabiendo la profecía dudaba a veces la animaba la Sierva bendita, diziéndola: No seas incrédula, no lo dudes, tú estarás entre ellas: lo qual se está verificando ahora mismo 3 de noviembre de 1727 en que se escribe esto pues a las doze les preside como Priora dicha Sor María. Hasta la Casa donde se juntarían insinuó la Venerable, que es, la que de limosna, por raro modo y providencia singular del Cielo, les compraron y dieron piadosas personas, verificándose la profecía a la letra. Otras muchas tuvo la Sierva de Dios que sería prolijo el referir para que se vea, quan particularmente estaba el Señor en su Espíritu iluminado, pues la manifestaba arcanos de lo futuro. Pero bastará lo aquí insinuado, para que el Letor piadosos conozca la grandeza del Gigante por el dedo (López Franco 1730: 329).

Finalmente, en 1725, se fundó el beaterio de santa Magdalena. Poco tiempo después se transformó en colegio de niñas ya bajo la advocación de santa Rosa, institución más acorde con los tiempos que el inicial beaterio. La figura de Josefa Verride, sin embargo, y a pesar de la transformación de la casa se siguió conociendo e identificando con la fundadora consiguiéndose así que su memoria perdurara en el tiempo. ${ }^{2}$

La memoria y el relato de Josefa se reforzaron en los testimonios recogidos para iniciar el proceso de beatificación. Fundamental es el de María Lay, ${ }^{3}$ una de sus discípulas y encargada tras su muerte de poner en marcha el beaterio, que pone de relieve el magisterio y liderazgo de Josefa en vida:

al principio que esta atestante tomó el habito de religiosa, concurrió muchas vezes a la casa de dicha sierva de dios en compañía de otras muchas mugeres pías, que son ya difuntas la mayor parte de ellas, a varios exercicios espirituales, porque todas la veneraban como a maestra, y tenían de ella grande concepto. ${ }^{4}$

Curiosamente en el testimonio no hace hincapié en la profecía de la fundación del beaterio sino en el magisterio y la actividad de Josefa al frente de ese grupo de mujeres.

2Aún hoy en la página del colegio que actualmente se llama Altoaragón aparece el nombre de Josefa Verride como fundadora del primitivo beaterio que luego evolucionó y se convirtió en colegio.

3En 1690 María Lay y Victoria Deza tomaron el hábito de beatas dominicas quedando bajo la dirección espiritual del confesor de Josefa y teniendo a esta como su maestra. (López Franco 1730: 28)

4 Archivio Segreto Vaticano, Congregazione dei Riti, Processus 2142, f. 133 r

SCRIPTA, Revista internacional de literatura i cultura medieval i moderna, núm. 8 / desembre 2016 / pp. 179-193 ISSN: 2340-4841 · doi:10.7203/SCRIPTA.8.9294 


\section{Conclusión}

Existían numerosas estrategias tanto de legitimación como de construcción y preservación de la imagen que las órdenes religiosas usaban en función de las características de cada mujer. Una de estas estrategias era vincular a la religiosa con figuras de relevancia en el momento, a modo de legitimadoras de su santidad. Tales son los casos de la beata franciscana Juana de la Cruz, que fue visitada en su convento de Cubas por el Emperador Carlos I y que contó entre sus protectores y benefactores con el Cardenal Cisneros y Gonzalo Fernández de Córdoba, el Gran Capitán. Del mismo modo la relación epistolar mantenida entre sor María de Ágreda y diferentes miembros tanto de la corte como de la familia real, destacando por encima de todas la de Felipe IV, le ayudaron a darse conocer y adquirir una fama que difícilmente hubiera estado a su alcance viviendo en un lugar como Ágreda apartado de los centros de poder del momento.

La escritura también fue otro de los instrumentos que sirvieron para dar a conocer a estas mujeres, y junto a grandes autoras como la citada sor María de Ágreda, conocemos en la actualidad el gran número de mujeres que con mayor o menor repercusión se dedicaron a la escritura auspiciadas por sus confesores o superiores masculinos.

Ninguna de estas herramientas fueron empleadas por los dominicos en los casos que nos ocupan. Ni Martina ni Josefa tuvieron, que se sepa, relación con miembros relevantes de la sociedad de su tiempo ni destacaron por sus dotes como escritoras. La estrategia utilizada con Martina fue la de vincularla con una tradición consolidada ya en el siglo XVII, que la relacionaba y conectaba con otras mujeres cuya santidad, o al menos sus grandes cualidades, no eran puestas en tela de juicio. Esta tradición era la obtención, posesión y puesta en circulación de cruces y cuentas de rosario bendecidas que había iniciado Juana de la Cruz. No era algo nuevo. La asociación de mujeres para potenciar su fama de santidad era conocida y empleada por las órdenes religiosas. Por ejemplo, la orden franciscana hizo partícipes a varias de las religiosas en toda una gesta: la muerte del rey de Suecia, Gustavo Adolfo, en la batalla de Lützen en 1632: ${ }^{5}$

Según el relato sor María de Ágreda, sor Juana Rodríguez y sor Marina de Escobar fueron llevadas por la divinidad al campo de batalla y allí, contribuyeron a la derrota y muerte del ejército protestante. La propia sor María portaba una imagen de la Inmaculada Concepción que lanzaba saetas, con la que hirió de muerte al rey sueco. (Morte 2010: 168-172)

¿Quiénes eran estas religiosas y cómo se tejió este relato?

5Entre el 16 y el 17 de noviembre de 1632, en el contexto de la guerra de los Treinta Años, se libró la batalla de Lützen entre las tropas imperiales comandadas por Wallenstein y las tropas suecas, al frente de las cuales iba el rey Gustavo Adolfo. La batalla se saldó con tablas, pero su importancia radica en que se puso fin a la oleada de victorias protestantes. La muerte del rey Gustavo Adolfo, en la noche del 16 de noviembre por tres heridas en el brazo, la espalda y la cabeza, fue un golpe emocional importante para ambos bandos. De hecho la veracidad de la noticia se siguió cuestionando mucho tiempo después. Parker 2003: 172. 
Juana Rodríguez de la Fuente, era religiosa en el convento de Santa Clara de Burgos, en el que había entrado en 1626 a la edad de 52 años, tras un matrimonio conflictivo. En la década de 1630, cuando acaeció el episodio de la batalla de Lützen, era una mujer muy conocida por la aparición de estigmas en sus manos y tenía fama de santa. Entre ella y sor María de Ágreda existía un elemento de conexión: el confesor de sor María, P. Fray Andrés de la Torre, ya que éste, cuando en 1634 la Inquisición comenzó a interesarse por el caso de Luisa de la Ascensión, siendo él provincial de la orden se entrevistó con Juana Rodríguez, y le recomendó que evitase las muestras públicas de sus experiencias sobrenaturales (Poutrin 1995: 316-317).

Marina de Escobar nació en Valladolid en 1554, tras sufrir una enfermedad que le dejó paralizada, pasó su vida en una oscura habitación a la que acudían los numerosos devotos que llegaban a visitarla. A pesar de su invalidez, Marina desarrollaba una actividad muy intensa: dirigía su pequeña comunidad de beatas, además de cultivar su relación con todo tipo de personas entre las que se encontraba el propio Felipe III y el Duque de Lerma. En 1615, doña Marina recibe la inspiración de fundar un convento de brígidas recoletas. El convento fue fundado en 1637, tras obtener todos los permisos necesarios y las bulas papales pertinentes, con la colaboración de las agustinas recoletas de Villafranca del Bierzo (Poutrin 1995: 303-304). ${ }^{6}$

En torno a 1632, tanto Juana Rodríguez como Marina de Escobar contaban con fama en la Monarquía hispánica y estaban relacionadas con personas de las clases sociales más altas e influyentes, aunque Marina aún no había llevado a cabo la fundación del convento. No es de extrañar por tanto, que la orden franciscana tuviera interés en que la fama de estas mujeres, a pesar de que Marina no fuera de su orden, se asociase a una religiosa que empezaba a adquirir reputación de santa, sor María de Ágreda -recordemos que su correspondencia con Felipe IV se inició en 1643-y puede que la mejor forma de hacerlo fuera uniéndolas en una cruzada para vencer al enemigo protestante.

En el caso de Martina y Josefa la orden dominica puso en marcha otra estrategia que consiguió igualmente vincularlas a tradiciones exitosas. La de las cuentas y cruces bendecidas que inició Juana de la Cruz en el caso de Martina haciendo además que apareciese en la vida de otras dominicas y en el caso de Josefa vinculándola con la fundación de un beaterio que posteriormente derivó en colegio. De esta manera lograron que estas dos mujeres que en principio tenían difícil el transitar con éxito el camino hacia la santidad, aunque no lo consiguieran de forma oficial, sí que lo consiguieran en la memoria colectiva.

6 Sobre su obra escrita ver también Poutrin (2007). 


\section{Bibliografía}

Atienza, Á (2007) «De beaterios a conventos. Nuevas perspectivas sobre el mundo de las beatas en la España Moderna», Historia Social, 57,1, pp.145-168.

-.(2012) Iglesia memorable. Crónicas, historias, escritos... a mayor gloria. Siglos XVI-XVIII, Madrid, Marcial Pons.

- (2014) «Las grietas de la clausura tridentina. Polémicas y limitaciones de las políticas de encerramiento de las monjas...Todavía con Felipe IV», Hispania, vol.74, n.248, pp. 807-834.

Faci, R. (1761) Vida de la V. Mariana Villalva y Vicente, y la de sus tres bijas Sor María, Sor Margarita y Sor Mariana Escobar, Pamplona.

López Franco, P. (1730) Comercio espiritual en fe de la Iglesia militante con la triunfante: practicado y esplicado en la vida y virtudes de la venerable virgen y sierva del Serñor sor Josepha Berride de la tercera orden de santo Domingo, Zaragoza.

Maya Salaberría, A. (1678) Vida prodigiosa y exercicio admirable de virtudes de la V.M. Sor Martina de los Angeles y Arilla, religiosa profesa de el religiosissimo Convento de santa Fe de Zaragoza, Orden de Predicadores, y fundadora de el de San Pedro Mártir, de la insigne villa de Benabarre, Zaragoza

Morte Acín, A. (2010) Misticismo y conspiración. Sor María de Ágreda en el reinado de Felipe IV, Zaragoza, Institución Fernando el Católico.

Morte Acín, A. (2014) «Sor María de Ágreda y la vida cotidiana en Ágreda en el siglo XVII: una aproximación histórica», Cuadernos de Historia Moderna, 39, pp.121-136.

Parker, G. (ed.) (2003) La Guerra de los Treinta Años, Madrid, Antonio Machado.

Poutrin, I. (1990) «Les chapelets bénits des mystiques espagnoles (XVI et XVII siècles)» en Melanges de la Casa de Velárquez, 26,2, pp. 33-54.

- (1995) Le voile et la plume. Autobiographie et sainteté feminine dans l'Espagne moderne, Madrid, Casa de Velázquez.

—_. (2007) «Una lección de teología moderna: la »Vida Maravillosa de doña Marina de Escobar« (1665)», en Historia Social, 57, pp.127-145.

Sánchez Lora, J.L. (1988) Mujeres, conventos y formas de la religiosidad barroca, Madrid, Fundación Universitaria Española.

Sanmartín R. (2012) La representación de las místicas: Sor María de santo Domingo en su contexto europeo, Santander, Propíleo 1. Real Sociedad Menéndez Pelayo.

Zarri,G. (1980) «Le sante vive. Per una tipologia della santità femminile nel primo '500», Annali del'Istituto storico italo-germanico in Trento, 6, pp. 371-445, -(1990) Le sante vive. Profezie di corte e devozione femminile tra '400 e '500, Turin, Rosenberg \& Sellier. 